\title{
Article \\ Multimodal Therapeutic Approach in Women with High Risk of Metabolic Syndrome-A Single Group One Center Pre-Post Study
}

\author{
Jagoda Rusowicz ${ }^{1, *(\mathbb{D}, \text { Anna Serweta }}{ }^{2}$, Wojciech Idzikowski ${ }^{2}$ and Joanna Szczepańska-Gieracha ${ }^{1}$ (1) \\ 1 Department of Physiotherapy, Wroclaw University of Health and Sport Sciences, 51-612 Wrocław, Poland; \\ joanna.szczepanska@awf.wroc.pl \\ 2 Department of Physical Education and Sport Sciences, Wroclaw University of Health and Sport Sciences, \\ 51-612 Wrocław, Poland; serwetanna@gmail.com (A.S.); wojciech.idzikowski@awf.wroc.pl (W.I.) \\ * Correspondence: jagodarusowicz@gmail.com
}

Citation: Rusowicz, J.; Serweta, A.; Idzikowski, W.; Szczepańska-Gieracha, J. Multimodal Therapeutic Approach in Women with High Risk of Metabolic Syndrome-A Single Group One Center Pre-Post Study. J. Clin. Med. 2021, 10, 4915. https:// doi.org/10.3390/jcm10214915

Academic Editor: Giuseppe La Torre

Received: 27 August 2021

Accepted: 22 October 2021

Published: 24 October 2021

Publisher's Note: MDPI stays neutral with regard to jurisdictional claims in published maps and institutional affiliations.

Copyright: (c) 2021 by the authors. Licensee MDPI, Basel, Switzerland. This article is an open access article distributed under the terms and conditions of the Creative Commons Attribution (CC BY) license (https:// creativecommons.org/licenses/by/ $4.0 /)$.

\begin{abstract}
The study aims to determine the impact of multimodal therapeutic approach on selfperceived stress in women with high risk of Metabolic Syndrome (MetS). The study involved 43 women aged 60 years and over (mean $68.6 \pm 6.5$ ) participating in a Mental Health Promotion Program. Over the 3-month course of the project, all of the participants attended meetings of a support group (60-min sessions twice a week). During these meetings, they took part in general fitness training (20 $\mathrm{min})$, dancing (20 $\mathrm{min})$, as well as health-promoting education and psychoeducation sessions (20 $\mathrm{min}$ ). Moreover, the participants were encouraged to modify their diet to reduce their daily fat and sugar intake. Stress levels were assessed using the Perception of Stress Questionnaire (PSQ). Mood was measured with the Geriatric Depression Scale (GDS-30). In all of the subjects, a body composition analysis was performed using a Tanita BC-545N analyzer. Abdomen and hip circumference were measured to determine the waist-hip ratio. Weight and height were measured to determine the BMI score. At the beginning of the project, the intensity of stress correlated with the level of depressive symptoms (GDS), Body Mass Index (BDI), and the amount of visceral fat. Three months of participation in the Mental Health Promotion Program resulted in a significant reduction in stress intensity $(p<0.01)$. At the end of the project, all of the participants expressed their willingness to continue their participation in the classes, which is very important as there is a need to conduct long-term health-promoting activities in the age group in question.
\end{abstract}

Keywords: postmenopausal age; stress; mood; mental health; obesity; public health

\section{Introduction}

From the years 2015 to 2050 , it is expected that the percentage of the world's population aged 60 or more will increase from $12 \%$ to $22 \%$ [1]. The world is facing the challenge of developing health and social care systems that will be prepared for these demographic changes. Its consequence will be a general increase in the incidence of cardiovascular disease, obesity, cancer, and other health issues typical for older age. Most of the elderly population are women (58\%), as there are 140 women per every 100 men [2,3]. Therefore, we must seek effective, universally applicable, and cost-effective programs for health promotion and disease prevention in the elderly population.

In the above context, given the complex mutual dependencies between health, physical fitness, and psychosocial problems, a biopsychosocial approach deserves particular attention. In this approach, great emphasis is placed on the group nature of all the activities (reducing the sense of loneliness and social isolation), on body training (general fitness training, relaxation, dance), as well as health promotion and psychoeducation. This holistic therapeutic approach must be carried out on a long-term basis by a multidisciplinary team of specialists (e.g., a physiotherapist, a psychotherapist, and a music therapist) experienced in working with older patients [4]. The biopsychosocial model can be used to 
improve clinical outcomes by building patients' awareness of the interactions between biological, psychological, socio-cultural factors, and to increase patients' self-management of illness [5].

The postmenopausal period is the time of the higher risk of mood disorders. Although not every person experiencing high-stress levels suffers from depression, these people are at high risk of developing depressive symptoms. Stress is a set of reactions the body responds with to stressors that place its coping abilities to test. The main causes of stress are change and the need to adapt to the biological, social, physical, and environmental requirements. The life changes experienced by the elderly become stressors that have a detrimental effect on their health and functioning. The postmenopausal period in women may have a significant role in the occurrence of adaptive disorders leading to high levels of stress. A decrease in estrogen production results in its reduced protective activity in the circulatory system, which, in consequence, increases the risk of cardiovascular diseases [6].

Our previous study demonstrated that low-intensity physical exercise used in a group setting combined with psychoeducation resulted in significant improvements in both depression and stress levels in women with MetS [7]. Dance intervention may be an effective adjunct therapy to improve mood and physical function in adults [8]. Moreover, it may be a relevant form of exercise for older adults due to social factors and accessibility [9]. Furthermore, dance, regardless of its style, can significantly improve muscular strength and endurance, balance, and other aspects of functional fitness in older adults [10]. As a result, we decided to include dance as an important element of our therapeutic program.

The study aims to determine the impact of multimodal therapeutic approach on selfperceived stress in women with high risk of Metabolic Syndrome (MetS), and to analyze the relationship between the level of perceived stress, mood, and the components of the MetS in a group of examined women.

\section{Materials and Methods}

\subsection{Design of the Study}

The study was identified as a single group one center study with pre-post design. The study was conducted in a group of 43 women aged 60 years and over (mean $68.6 \pm 6.5$ ), participating in the Mental Health Promotion Program at the Foundation for Senior Citizen Activation SIWY DYM in Wroclaw, Poland. The participants received a referral to the therapeutic program from their primary care physician due to a high risk of MetS. All of the patients received permission to participate in moderate intensity physical training.

Both the study and the therapeutic program lasted 3 months (12 weeks). Two measurement points were established. The first outcome measurement was taken immediately before the therapeutic program began and it included the assessment of the stress level and mood. The second measurement was conducted 3 months after the start of the study, at the end of the therapeutic intervention (Figure 1). The measurements and analyses were performed by a psychologist experienced in this area.

Body composition and anthropometric measurements (body height and weight, waist and hip ratio), as well as blood pressure and laboratory tests (e.g., blood results, fasting sugar levels) were ordered by a primary care physician only once, at the time of project recruitment.

The project received funding from the Municipality of Wroclaw. Approval to conduct the study was obtained from the Bioethics Committee of the Wroclaw University of Health and Sport Sciences in Wroclaw (No. 16.06.14). Informed consent was obtained from all of the subjects involved in the project. The study was conducted in accordance with the Helsinki Declaration. 


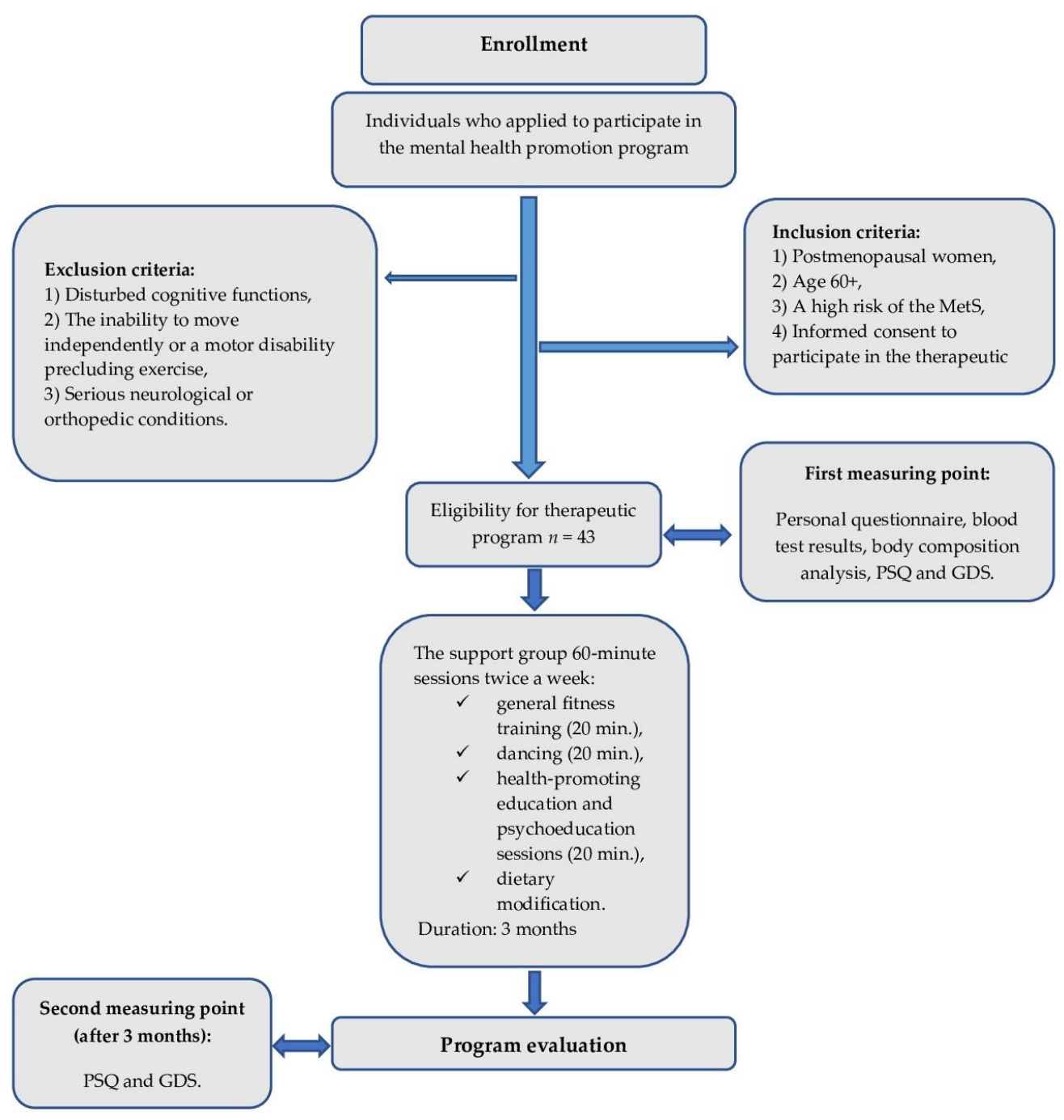

Abbreviations: PSQ - Perception of Stress Questionnaire; GDS - Geriatric Depression Scale; MetS - metabolic syndrome.

Figure 1. Flow chart of the recruitment process towards the study group.

\subsection{Inclusion Criteria for the Research Project}

A high risk of the MetS was diagnosed using the criteria recommended by the International Diabetes Federation (IDF): Central obesity (defined as waist circumference $\geq 80 \mathrm{~cm}$ in females), raised triglycerides $(>150 \mathrm{mg} / \mathrm{dL})$, reduced HDL cholesterol $(50 \mathrm{mg} / \mathrm{dL}$ in females), elevated blood pressure (BP; systolic BP > 130 or diastolic $\mathrm{BP}>85 \mathrm{~mm} \mathrm{Hg}$ ), and increased fasting plasma glucose $>100 \mathrm{mg} / \mathrm{dL}[11,12]$. The presence of two of the five characteristics listed above qualified subjects for the project. The exclusion criteria included disturbed cognitive functions, the inability to move independently or a motor disability precluding exercise, serious neurological or orthopedic conditions (e.g., advanced Parkinson's disease, severe stroke consequences). The classification of normal blood pressure and hypertension is in accordance with the European guidelines ESH/ESC 2018 and is based on the limit value RR $140 / 90 \mathrm{~mm} \mathrm{Hg}$ with a division into three steps (optimal < 120/80 mm Hg; normal up to $129 / 84 \mathrm{~mm} \mathrm{Hg}$; high normal up to $139 / 89 \mathrm{~mm} \mathrm{Hg}$ ) and distinction of the Insulated Subtype Systolic Hypertension (ISH) [13,14]. Patients were recruited to the project by their primary care physicians based on the results of medical tests and anthropometric 
measurements. We do not have information on the number of people who had been screened but did not meet the inclusion criteria for the project.

\subsection{Measurements}

The Perception of Stress Questionnaire (PSQ) by Plopa (2010) was used to assess the stress levels. The questionnaire is designed to measure the structure of stress experiences. The questionnaire allows the calculation of a general score, which indicates the generalized stress level, as well as three results referring to the following dimensions: Emotional tension, external stress, and intrapsychic stress. The questionnaire comprises 27 statements and the respondent determines the degree to which a given statement concerns him or her, using a five-level Likert scale ranging from "True" to "False". In each of the areas (emotional tension, external stress, intrapsychic stress), there are seven statements, indicating that in each area the respondent can score between 7 and 35 points. Then, all of the points are summed up to calculate an overall score, and the score can range between 21 and 105 points. The remaining six statements in the questionnaire relate to the lying scale (from 6 to 30 points). The raw score is converted into a STEN score for gender and age, respectively. A score of 7-10 STEN indicates a feeling of increased nervousness, anxiety, and problems with relaxation. A score of 5-6 indicates average intensity of emotional tension. A score of 1-4 indicates no emotional strain. The results of the individual stress components are interpreted in a similar way. The internal consistency rates for the three scales (dimensions) in the examination of adults were between 0.70 and 0.81 . The factor validity of the PSQ was confirmed [15].

Mood was assessed using the Geriatric Depression Scale (GDS), developed by Yesavage et al. (1988) as a screening instrument to evaluate the intensity of depression in older adults [16]. It consists of 30 short questions with two possible answers ("Yes" or "No"). A score between 0-9 points indicates normal mood, a score between 10-19 points indicates mild depression, and a score greater than 19 points represents a severe form of depression. The reliability of the GDS was estimated using the Cronbach $\alpha$ coefficient and the Spearman-Brown split-half reliability formula. Cronbach's alpha reliability coefficient was $\alpha=0.94$, and an identical coefficient value $(\mathrm{r}=0.94)$ was obtained in the split-half reliability measurement of this instrument. The sensitivity and specificity of the GDS were found to be $84 \%$ and $95 \%$, respectively $[17,18]$.

In all of the subjects, a body composition analysis was performed using a Tanita $\mathrm{BC}-545 \mathrm{~N}$ analyzer. Abdomen and hip circumference were measured to determine the waist-hip ratio. Weight and height were measured to determine the BMI score. All of these tests, as well as blood pressure measurement and blood analysis, were ordered by a physician and performed in a medical setting.

\subsection{Intervention}

Throughout the therapeutic program, all of the participants attended meetings of the support group (60-min sessions twice a week). During these meetings, they took part in a general fitness training ( $20 \mathrm{~min}$ ) run by a physiotherapist, a dance session $(20 \mathrm{~min})$ run by a music therapist, as well as health-promoting education and psychoeducation sessions (20 min) run by a psychotherapist. Each class was conducted in a small, fixed group of 10-12 women. Participants were divided into smaller groups at random. General fitness exercises were aimed at increasing muscle strength and improving the range of motion in large joints. A single exercise session lasted $20 \mathrm{~min}$ and consisted of 22 low-intensity, general fitness exercises. Thirteen exercises were done sitting down, seven standing, and two in the hand-and-knees position. The exercises were classified as either aerobic, musculo-articular or stabilizing. The aerobic portion served as a general warm-up for the subsequent exercises, and the musculo-articular section focused on strengthening muscles and enhancing the mobility of joints in the upper limbs, lower limbs, and the torso. The stabilizing exercises were designed to improve the stability of the body and to augment 
spatio-visual coordination. Moreover, the intensity of exercise was low and was intended as a warm-up for the subsequent dance session.

To ensure safety, the fitness exercises and partly the dance sessions were carried out in a sitting position on specially adapted stable chairs. In the initial part of the session, the music was characterized by a slow tempo, a peaceful character, and a stable rhythmic layer. The session used Cuban music and basic salsa steps. The pace was adjusted to the participants' abilities. When the dancing became tiresome, the participants ended the session in a sitting position. At the peak of the training session, the exercise intensity reached a moderate level. However, each person was informed that the intensity of the exercises could not exceed 14 points on the 20-items Borg Scale (an effort described as "somewhat hard") [19]. The load lasted no more than $1 \mathrm{~min}$ and was introduced gradually from the beginning of the project. Each participant could stop the exercises at any time and rest until the level of fatigue decreased to a moderate or low level.

All of the support group meetings were developed by a therapeutic team-a psychotherapist, a physiotherapist, and a music therapist. As a part of the educational activities, participants were encouraged to modify their diets: To reduce white flour and sugar foods and increase the consumption of healthy oils and vegetables in their daily menu. The presence of a psychotherapist during all of the classes was intended to accelerate and strengthen the relationship-building processes within the group, as well as to model and reinforce attitudes of openness, cooperation, and mutual support in achieving common goals.

\subsection{Statistical Methods}

The statistical analysis was performed using the STATISTICA 13.3 software by TIBCO Software Inc. (StatSoft Polska, Kraków, Poland). The statistical significance threshold was set at $p<0.05$. The statistical description of the data included, in the case of characteristics with continuous distributions: Determination of the mean, standard deviation, and variability range (the minimum and maximum values in an empirical distribution). Moreover, distributions of continuous characteristics were presented as the distribution series. The normality of the distribution of the continuous characteristics was determined using the Shapiro-Wilk test. The null hypothesis on the normality of distribution was rejected in the case of most components of stress and GDS values. Therefore, the nonparametric Spearman correlation coefficient $(\rho)$ was used to evaluate the interdependence between the characteristics (the correlation of stress with age, the GDS, the BMI, and visceral fat). The non-parametric Wilcoxon rank test was used to analyze the pre-post psychological parameters. Due to the sensitive nature of the data analyzed in the current study (protected medical information), they are available from the authors upon request.

The sample size for our study was a minimum of 40 subjects with a confidence level of $95 \%$, a fraction size estimated at $40 \%$, and an assumed maximum error of $15 \%$.

\section{Results}

\subsection{First Measurement Point}

The detailed characteristics of the study group at the beginning of the therapeutic program are shown in Table 1.

In addition to obesity, other factors predisposing the subjects to the occurrence of the MetS were present in the study group. One of these was hypertension, present in 28 women and untreated in only one person. Another factor was the fasting plasma glucose of more than $100 \mathrm{mg} / \mathrm{dL}$ or the treated type II diabetes, which occurred in $44 \%$ of the study group. A raised triglyceride level was detected in $28 \%$ of participants, among whom $67 \%$ were under pharmacological treatment. The results are presented in Table 2. 
Table 1. Participants' baseline characteristic, $n=43$.

\begin{tabular}{|c|c|c|}
\hline \multicolumn{3}{|c|}{ Total $n=43($ mean \pm SD $)$} \\
\hline \multicolumn{2}{|c|}{ Age (years) } & $68.6 \pm 6.5$ \\
\hline \multicolumn{2}{|c|}{ Mass (kg) } & $73.2 \pm 17.9$ \\
\hline \multicolumn{2}{|c|}{ Height (m) } & $159.6 \pm 6.0$ \\
\hline \multicolumn{2}{|c|}{$\mathrm{BMI}\left(\mathrm{kg} / \mathrm{cm}^{2}\right)$} & $28.9 \pm 6.2$ \\
\hline \multicolumn{2}{|c|}{ Waist Circumference (cm) } & $97 \pm 14.3$ \\
\hline \multicolumn{2}{|c|}{ Hips Circumference (cm) } & $113 \pm 16.4$ \\
\hline \multicolumn{2}{|c|}{ WHR } & $0.86 \pm 0.08$ \\
\hline \multirow{3}{*}{ Education (\%) } & Basic/vocational & 15 \\
\hline & Secondary & 51 \\
\hline & Higher education & 34 \\
\hline \multirow{4}{*}{ Marital status (\%) } & Married & 37 \\
\hline & Single & 24 \\
\hline & Divorced & 7 \\
\hline & Widowed & 32 \\
\hline \multirow[t]{4}{*}{ Body weight classification (\%) } & Normal weight & 25 \\
\hline & Overweight & 39 \\
\hline & Class I obesity & 22 \\
\hline & Class II obesity & 14 \\
\hline \multirow[t]{3}{*}{ Mood and well-being (\%) } & Lack of depression & 76 \\
\hline & Moderate depression & 22 \\
\hline & Severe depression & 2 \\
\hline
\end{tabular}

Abbreviations: BMI—body mass index; WHR—waist-hip ratio; SD—standard deviation.

Table 2. Laboratory tests results and blood pressure of the women in the study group.

\begin{tabular}{cccccc}
\hline \multicolumn{2}{c}{ Feature } & Mean & SD & Minimum & Maximum \\
\hline \multirow{2}{*}{$\begin{array}{c}\text { Blood pressure } \\
(\mathrm{mmHg})\end{array}$} & systolic & 134.9 & 21.2 & 90 & 184 \\
\cline { 2 - 6 } & diastolic & 74.8 & 10.2 & 52 & 98 \\
\hline \multirow{2}{*}{$\begin{array}{c}\text { Cholesterol } \\
(\mathrm{mg} / \mathrm{dL})\end{array}$} & total & 211.5 & 42.1 & 149 & 342 \\
\cline { 2 - 6 } & HDL & 70.6 & 23.8 & 42 & 183 \\
\hline \multicolumn{2}{c}{ Triglycerides (mg/dL) } & 118.7 & 39.9 & 63 & 238 \\
\hline \multicolumn{2}{c}{ Blood sugar level (mg\%) } & 120.5 & 47.2 & 48 & 253 \\
\hline
\end{tabular}

Abbreviations: HDL—high-density lipoprotein; LDL—low-density lipoprotein; SD—standard deviation.

First, the body composition results were analyzed, including the parameter determining the amount of visceral fat tissue, which is an indicator of central obesity (Table 3). The analysis was necessary to assess the risk of metabolic syndrome.

\subsection{Correlation Analysis}

At the beginning of the therapeutic program, stress correlated with the level of depressive symptoms $(p=0.00, \mathrm{R}=0.61)$, the BMI value $(p=0.02, \mathrm{R}=0.39)$, and the amount of visceral fat ( $p=0.05, \mathrm{R}=0.33$ ). Across the stress components, BMI correlated most strongly with external and intrapsychic stress $(p=0.02, \mathrm{R}=0.4)$, and body fat correlated with internal stress $(p=0.03, \mathrm{R}=0.36)$. This means that the higher the level of perceived stress, the worse the sense of well-being, the higher the BMI value and the amount of 
visceral fat. This applies to both the result of the general stress assessment and to its components: Emotional tension, external stress, and intrapsychic stress. R-values in the range of 0.2-0.4 are interpreted as low correlation (visible relationship), while $0.4-0.6$ corresponds to moderate correlation (significant relationship), and a score of $0.6-0.8$ indicates high correlation (significant relationship). Table 4 presents the results of the correlation analysis. The correlation coefficients significant at the level of $p<0.05$ are indicated by the "**" symbol.

Table 3. Parameters of the distribution of body composition characteristics of the women examined.

\begin{tabular}{ccccc}
\hline Feature & Mean & SD & Minimum & Maximum \\
\hline Fat $(\%)$ & 38.9 & 6.9 & 21.1 & 50.2 \\
\hline Water Composition (\%) & 44.2 & 4.6 & 36.5 & 55.2 \\
\hline Muscle Mass (kg) & 41.7 & 7.4 & 28.6 & 58.9 \\
\hline Bone Mass (kg) & 2.2 & 0.4 & 1 & 3.1 \\
\hline Basal Metabolic Rate (kcal) & 1332.8 & 238.3 & 983 & 1947 \\
\hline Visceral Fat & 11 & 2.9 & 6.5 & 19 \\
\hline
\end{tabular}

Table 4. The coefficients of correlation of stress with age, the GDS, the BMI, and visceral fat in the study group.

\begin{tabular}{ccccc}
\hline \multirow{2}{*}{ Stress Components } & \multicolumn{4}{c}{ Spearman's Rank Correlation Coefficient } \\
\cline { 2 - 5 } & Age & GDS & BMI & Visceral Fat \\
\hline Emotional tension & $0.1, p=0.52$ & $0.57^{*} p=0.00$ & $0.31 p=0.06$ & $0.3 p=0.08$ \\
\hline External stress & $0.13, p=0.40$ & $0.53 * p=0.00$ & $0.4 * p=0.02$ & $0.32 p=0.06$ \\
\hline Intrapsychic stress & $0.19, p=0.23$ & $0.52 * p=0.00$ & $0.4 * p=0.02$ & $0.36 * p=0.03$ \\
\hline General PSQ score & $0.15, p=0.35$ & $0.61 * p=0.00$ & $0.39 * p=0.02$ & $0.33 * p=0.05$ \\
\hline
\end{tabular}

Abbreviations: GDS—geriatric depression scale; BMI—body mass index; PSQ—perception of stress questionnaire;

* - correlation coefficients significant at $p<0.05$.

\subsection{Second Measurement Point: Pre-Post Analysis}

The GDS and the PSQ were applied again after 3 months of regular participation in the therapeutic program. The results indicated a significant reduction in stress intensity (overall stress score and external stress score). A comparison of the pre-post scores obtained with the psychological tools is provided in Table 5. The distribution of the PSQ STEN values in the pre-post analysis is shown in Table 6.

Table 5. Effects of a 3-month intervention on the results of GDS and PSQ scales in the Wilcoxon rank test.

\begin{tabular}{|c|c|c|c|c|c|c|c|}
\hline$N=43$ & Mean & SD & Minimum & Maximum & $p$-Value & $\mathrm{Z}$ & $\mathrm{T}$ \\
\hline \multicolumn{8}{|c|}{ GDS } \\
\hline Before & 6.95 & 5.66 & 0 & 30 & & & \\
\hline After & 6.79 & 5.18 & 0 & 20 & & & \\
\hline Change & 0.16 & & & & NS & 0.337 & 246.00 \\
\hline \multicolumn{8}{|c|}{ General PSQ Score } \\
\hline Before & 60.53 & 18.28 & 23 & 104 & & & \\
\hline After & 49.81 & 16.41 & 22 & 83 & & & \\
\hline Change & 10.72 & & & & $<0.001$ & 4.095 & 124.00 \\
\hline
\end{tabular}


Table 5. Cont.

\begin{tabular}{|c|c|c|c|c|c|c|c|}
\hline$N=43$ & Mean & SD & Minimum & Maximum & $p$-Value & $\mathbf{Z}$ & $\mathrm{T}$ \\
\hline \multicolumn{8}{|c|}{ Emotional Tension } \\
\hline Before & 18.21 & 6.97 & 7 & 32 & & & \\
\hline After & 18.33 & 7.34 & 7 & 35 & & & \\
\hline Change & -0.12 & & & & NS & 0.283 & 351.00 \\
\hline \multicolumn{8}{|c|}{ External Stress } \\
\hline Before & 16.91 & 5.32 & 8 & 30 & & & \\
\hline After & 14.30 & 4.70 & 7 & 25 & & & \\
\hline Change & 2.61 & & & & $<0.001$ & 3.734 & 113.00 \\
\hline \multicolumn{8}{|c|}{ Intrapsychic Stress } \\
\hline Before & 17.91 & 5.61 & 7 & 30 & & & \\
\hline After & 17.19 & 6.35 & 7 & 31 & & & \\
\hline Change & 0.72 & & & & NS & 1.584 & 276.50 \\
\hline
\end{tabular}

Abbreviations: GDS—geriatric depression scale; SD—standard deviation; NS—non significant.

Table 6. Distribution of stress level scores in the study group in STEN (the higher the STEN, the higher the stress level).

\begin{tabular}{ccc}
\hline STEN & PRE\% & POST\% \\
\hline 1 & 5 & 23 \\
\hline 2 & 9 & 19 \\
\hline 3 & 16 & 9 \\
\hline 4 & 21 & 16 \\
\hline 5 & 18 & 19 \\
\hline 6 & 14 & 7 \\
\hline 7 & 5 & 5 \\
\hline 8 & 7 & 0 \\
\hline 9 & 0 & 0 \\
\hline 10 & 5 & 2 \\
\hline
\end{tabular}

The distribution of the PSQ STEN values allows the observation of a noticeable change ( $p<0.01 ; Z=3.9)$ in the level of perceived stress, especially for the 1 and 2 STEN values (an increase in the number of people with the lowest levels of stress). Moreover, it is worth noting the reduction in the number of people with the highest levels of stress (6-10 STEN) (Table 6).

\section{Discussion}

The purpose of this study was to determine the impact of multimodal therapeutic approach on self-perceived stress in women with metabolic syndrome (MetS), and to analyze the relationship between the level of perceived stress, mood, and the components of the MetS in women aged 60 years and older. The participants of the Mental Health Promotion Program were postmenopausal women. They decided to participate in the project to take care of their health and improve their quality of life. A unique aspect of the study was a group multimodal therapeutic approach of a biopsychosocial nature. Activities offered by the Foundation for Senior Citizen Activation SIWY DYM are aimed at supporting the treatment of civilization diseases through non-pharmacological forms of therapy. The project included activities such as general fitness training, dance, as well as health-promoting education and psychoeducation. 
The enrichment of the therapeutic activities with art-based activities, i.e., active participation in dance sessions, may have contributed to the effectiveness of the described project in terms of stress reduction. Obviously, as with all of the multimodal approaches, we are not able to determine the extent to which individual elements of the project contributed to the outcome achieved. The positive impact of this approach comes precisely from the fact that the various components of the project complement each other. In this case, the components were physical exercise, dance, and health education.

The possibility of effective use of dance not only in the case of physical, but also psychological and social problems, makes it an integral element of the multimodal therapeutic approach in our experiment. Unfortunately, there is not enough research on the subject that would allow the comparison of our findings. One of the few studies examining the application of dance to high-risk MetS is the study on the impact of rumba dance and nutrition education interventions on cardiovascular risk factors in a group of people with MetS in rural Colombia. The researchers reported that the program using rumba and muscular strengthening, combined with nutrition education, favorably modified cardiovascular risk factors in people with MetS [20]. Hofgaard et al. [21] studied the impact of a Faroese chain dance intervention on the health profile, mobility, and postural balance in elderly subjects. They found that the Faroese chain dance has a beneficial effect on postural balance and physical function, and most likely on blood pressure and body fat content, in elderly participants after only 6 weeks of training.

Interestingly, although the researchers' focus was on assessing changes related to physical functioning, they also emphasized the importance of dance as an integral part of identity and culture. In addition, the researchers pointed out the social benefits of dance intervention in a specific ethnic group. Dance improves social interaction and enjoyment and may overcome barriers to physical activity in older adults, which was also reflected in our study [21,22]. During our project, the group of participants became close to one another, the women formed bonds, supported each other, overcame the barriers of shame, and decided to freely express their emotions through dance.

In general, physical exercise affects both physical health parameters and mental health. Moreover, exercise has a positive effect on conditions often co-occurring with mood disorders (e.g., anxiety, pain, and insomnia) [23]. Chronic unresolvable stress leads to the development of mood disorders and cardiovascular disease [24]. In our study, a pre-post comparison showed that the level of perceived stress was significantly reduced after 3 months of regular participation in the therapeutic program. Comparing the results of the cited studies with the results obtained in our project, it can be concluded that the women who participated in the project received appropriate help. These are very promising findings, although they should be treated with caution due to the nature of the study design and the small sample size.

The correlations we explored in this study were largely in line with expectations (the higher the stress level, the worse the mood). However, the correlations of particular stress components (emotional tension, external stress, intrapsychic stress) with the BMI and visceral fat were interesting. The problem of overweight and obesity is related not only to eating habits, but is undeniably associated with mental factors such as the perceived stress or the experienced internal conflicts, including intramental conflicts. Moreover, obesity correlates with the deterioration of executive functions. It is believed that new interventions should be developed, which would take into account mood and emotion regulation in the treatment of obesity [25]. In our opinion, it is worthwhile for future studies to focus on the in-depth meaning and impact of particular stress components on the components of MetS. This could help in better adapting the activities and content of health education to the needs of patients with MetS.

It is worth noting that addressing dietary modification and changing eating habits was an important part of the education in this program. Perhaps the next step could be for a specialist to develop a personalized diet for each participant. Castro-Barquero et al. [26] reported that lifestyle modifications, especially dietary habits, are the main 
therapeutic strategy for the treatment and management of MetS, but the most effective dietary pattern for its management has not been established. Specific dietary modifications, such as improving the quality of the foods or changing macronutrient distribution, showed beneficial effects on MetS parameters. Moreover, energy-restricted dietary patterns and an increase in physical activity are crucial to improve the metabolic disturbances observed in metabolic syndrome patients. However, in our opinion, these restrictions should be introduced gradually, when the motivation of the participants is already very strong.

The prevalence of the MetS increases after the menopause and its dominant component (obesity) increases the prevalence and severity of menopausal symptoms [27]. Evidence shows that individuals with MetS have a significantly reduced health-related quality of life compared to those without the syndrome. Furthermore, the deterioration of the overall physical and mental health increases along with the number of MetS components presented in a patient [27-29]. Results from other studies suggest that the relationship between MetS, obesity, mood, and cardiovascular risk is complex. In fact, women with depression, emotional tension, stress, and anger show a higher risk of developing insulin resistance, MetS, and cardiovascular disease [27,30]. Eschweiler [31] argued that the multifactorial genesis of depression in the elderly includes psychosocial, vascular, and metabolic factors and requires multimodal treatment modules at the biological and psychosocial levels. We consider that MetS should be treated analogously. The analysis of the literature and our previous study [7] show that a biopsychosocial approach may be crucial in the treatment of these complex problems. We see our current study as an exploratory one that will allow us to continue our research and optimize therapeutic interventions in a group of postmenopausal women at high risk of MetS.

Civilization diseases are a major problem all over the world. The complexity of health problems concerning women aged 60 years and older make it necessary to develop effective and low-cost strategies involving biopsychosocial interventions. The incorporation of the general fitness training, dancing, health-promoting education, and psychoeducation sessions as therapeutic procedures can be an effective and interesting way to support the multi-faceted treatment of civilization diseases, including MetS. At the end of the project, all of the participants expressed their willingness to continue their participation in the classes, which is very important as there is a need to conduct long-term health-promoting activities in the age group in question.

\section{Limitations}

A major limitation of our study is the lack of a control group. Therefore, a randomized clinical trial should be planned for the next stage of the investigation. Both a control group without any intervention and a control group of patients participating in regular physical activity but without therapeutic components should be considered. The strength of the findings will be greater if the group of patients with MetS is significantly larger.

\section{Conclusions}

The level of perceived stress in the study group was related to the presence of depressive symptoms, BMI, and the amount of visceral fat in the study group. A multimodal therapeutic program including general exercise training, dance, health education, and psychoeducation is an interesting approach to reduce stress levels. However, due to the small sample size and other limitations of the project, the results should be treated with caution.

Author Contributions: Conceptualization, J.S.-G.; methodology, J.S.-G. and J.R.; software, W.I.; validation, J.R., formal analysis, J.R.; investigation, J.R. and A.S.; resources, J.S.-G.; data curation, J.R.; writing—original draft preparation, J.R., writing—review and editing, J.R., A.S., W.I., J.S.-G.; visualization, J.R.; supervision, J.S.-G.; project administration, W.I.; funding acquisition, W.I. and J.S.-G. All authors have read and agreed to the published version of the manuscript. 
Funding: The study was carried out at the Foundation for Senior Citizen Activation SIWY DYM in Wroclaw within a Mental Health Promotion Program. The project received funding from the Municipality of Wroclaw D/WZD/2264/1/2019.

Institutional Review Board Statement: The study was conducted according to the guidelines of the Declaration of Helsinki, and approved by the Bioethics Committee of the Wroclaw University of Health and Sport Sciences in Wroclaw (16.06.14).

Informed Consent Statement: Informed consent was obtained from all of the subjects involved in the study.

Data Availability Statement: The data presented in this study are available on request from the corresponding author. The data are not publicly available due to privacy restrictions.

Acknowledgments: We are very grateful to the Foundation for Senior Citizen Activation SIWY DYM, and the Municipality of Wroclaw for the financial support of the Mental Health Promotion Program.

Conflicts of Interest: The author(s) declare no potential conflict of interest with respect to the research, authorship, and/or publication of this article.

\section{References}

1. WHO. Ageing and Health. Available online: https://www.who.int/en/news-room/fact-sheets/detail/ageing-and-health (accessed on 22 March 2020).

2. Zając, K.; Serweta, A.; Salamon-Krakowska, K.; Szczepańska-Gieracha, J. The level of stress experienced in women over the age of 60 who take regular physical activity and pro-health activities. Contemporary Gerontology. 2017, 5, $120-124$.

3. Statistics Poland. The situation of older people in Poland in 2018; Statistics Poland: Warsaw, Poland, 2018.

4. Szczepańska-Gieracha, J.; Mazurek, J.; Serweta, A.; Boroń-Krupińska, K.; Kowalska, J.; Skrzek, A. Effectiveness Assessment of a Therapeutic Programme for Women with Overweight and Obesity: A Biopsychosocial Perspective. Fam. Med. Prim. Care Rev. 2019, 21, 381-386. [CrossRef]

5. Kusnanto, H.; Agustian, D.; Hilmanto, D. Biopsychosocial Model of Illnesses in Primary Care: A Hermeneutic Literature Review. J. Fam. Med. Prim. Care 2018, 7, 497. [CrossRef] [PubMed]

6. Raczkiewicz, D.; Bojar, I.; Wdowiak, A.; Rzeźnicki, A.; Krakowiak, J. Stress at Intellectual Work and Cardiovascular Diseases in Women at Non-Mobility Working Age. Ann. Agric Environ. Med. 2019, 26, 456-461. [CrossRef] [PubMed]

7. Morga, P.; Cieślik, B.; Sekułowicz, M.; Bujnowska-Fedak, M.; Drower, I.; Szczepańska-Gieracha, J. Low-Intensity Exercise as a Modifier of Depressive Symptoms and Self-Perceived Stress Level in Women with Metabolic Syndrome. J. Sports Sci. Med. 2021, 20, 222-228. [CrossRef]

8. Murrock, C.J.; Graor, C.H. Effects of Dance on Depression, Physical Function, and Disability in Underserved Adults. J. Aging Phys. Act. 2014, 22, 380-385. [CrossRef]

9. McNeely, M.E.; Duncan, R.P.; Earhart, G.M. Impacts of Dance on Non-Motor Symptoms, Participation, and Quality of Life in Parkinson Disease and Healthy Older Adults. Maturitas 2015, 82, 336-341. [CrossRef]

10. Hwang, P.W.-N.; Braun, K.L. The Effectiveness of Dance Interventions to Improve Older Adults' Health: A Systematic Literature Review. Altern. Ther. Health Med. 2015, 21, 64-70.

11. Alberti, K.G.M.M.; Zimmet, P.; Shaw, J. Metabolic Syndrome-a New World-Wide Definition. A Consensus Statement from the International Diabetes Federation. Diabet Med. 2006, 23, 469-480. [CrossRef]

12. International Diabetes Federation. The IDF Consensus Worldwide Definition of the Metabolic Syndrome; International Diabetes Federation: Brussels, Belgium, 2006.

13. Tykarski, A.; Mastalerz-Migas, A.; Wieczorowska-Tobis, K.; Kokoszka-Paszkot, J.; Kusz-Rynkun, A.; Rymaszewska, J.; BujnowskaFedak, M.; Neumann-Podczaska, A.; Bień, B.; Siebert, J.; et al. REcomMEndations for DIAgnostics and maNagemenT of arterial hypertension in adults aged 65 years and older for General Practitioners-REMEDIA NT 65+ GP. Lek. POZ/Gen. Pract. 2018, 22, 263-288. [CrossRef]

14. Williams, B.; Mancia, G.; Spiering, W.; Agabiti Rosei, E.; Azizi, M.; Burnier, M.; Clement, D.L.; Coca, A.; de Simone, G.; Dominiczak, A.; et al. 2018 ESC/ESH Guidelines for the Management of Arterial Hypertension. Eur. Heart J. 2018, 39, $3021-3104$. [CrossRef] [PubMed]

15. Plopa, M.; Makarowski, R. The Perception of Stress Questionnaire; Vizja Press \& IT: Warszawa, Poland, 2010; ISBN 978-83-61086-79-6.

16. Yesavage, J.A. Geriatric Depression Scale. Psychopharmacol. Bull. 1988, 24, 709-711.

17. Albiński, R.; Kleszczewska-Albińska, A.; Bedyńska, S. Geriatric Depression Scale (GDS). Validity and reliability of different versions of the scale-Review. Psychiatr. Pol. 2011, 45, 555-562.

18. Yesavage, J.A.; Sheikh, J.I. 9/Geriatric Depression Scale (GDS): Recent Evidence and Development of a Shorter Version. Clin. Gerontol. 1986, 5, 165-173. [CrossRef]

19. Borg, G. Borg's Perceived Exertion and Pain Scales; Human Kinetics Publishers: Champaign, IL, USA, 1998; ISBN 0-88011-623-4. 
20. Pérez-Idárraga, A.; Valencia Gómez, K.; Gallo Villegas, J.; Arenas Sosa, M.; Quintero Velásquez, M.A. Intervention with rumba and nutrition education to modify cardiovascular risk factors in adults with metabolic syndrome. Rev. Panam. Salud Publ. 2015, 37, 29-37.

21. Hofgaard, J.; Ermidis, G.; Mohr, M. Effects of a 6-Week Faroese Chain Dance Programme on Postural Balance, Physical Function, and Health Profile in Elderly Subjects: A Pilot Study. BioMed. Res. Int. 2019, 2019, 1-9. [CrossRef] [PubMed]

22. Guzmán-García, A.; Hughes, J.C.; James, I.A.; Rochester, L. Dancing as a Psychosocial Intervention in Care Homes: A Systematic Review of the Literature: Dance Research in Dementia. Int. J. Geriatr. Psychiatry 2013, 28, 914-924. [CrossRef]

23. Hearing, C.M.; Chang, W.C.; Szuhany, K.L.; Deckersbach, T.; Nierenberg, A.A.; Sylvia, L.G. Physical Exercise for Treatment of Mood Disorders: A Critical Review. Curr. Behav. Neurosci. Rep. 2016, 3, 350-359. [CrossRef]

24. Brooks, S.; Brnayan, K.W.; DeVallance, E.; Skinner, R.; Lemaster, K.; Sheets, J.W.; Pitzer, C.R.; Asano, S.; Bryner, R.W.; Olfert, I.M.; et al. Psychological Stress-Induced Cerebrovascular Dysfunction: The Role of Metabolic Syndrome and Exercise. Exp. Physiol. 2018, 103, 761-776. [CrossRef]

25. Favieri, F.; Forte, G.; Casagrande, M. The Executive Functions in Overweight and Obesity: A Systematic Review of Neuropsychological Cross-Sectional and Longitudinal Studies. Front. Psychol. 2019, 10, 2126. [CrossRef]

26. Castro-Barquero, S.; Ruiz-León, A.M.; Sierra-Pérez, M.; Estruch, R.; Casas, R. Dietary Strategies for Metabolic Syndrome: A Comprehensive Review. Nutrients 2020, 12, 2983. [CrossRef] [PubMed]

27. Chedraui, P.; Pérez-López, F.R.; Hidalgo, L.; Villacreses, D.; Domínguez, A.; Escobar, G.S.; Genazzani, A.R.; Simoncini, T.; Research Group for the Omega Women's Health Project. Evaluation of the Presence and Severity of Menopausal Symptoms among Postmenopausal Women Screened for the Metabolic Syndrome. Gynecol. Endocrinol. 2014, 30, 918-924. [CrossRef] [PubMed]

28. Tziallas, D.; Kastanioti, C.; Kostapanos, M.S.; Skapinakis, P.; Elisaf, M.S.; Mavreas, V. The Impact of the Metabolic Syndrome on Health-Related Quality of Life: A Cross-Sectional Study in Greece. Eur. J. Cardiovasc. Nurs. 2012, 11, 297-303. [CrossRef] [PubMed]

29. Okosun, I.S.; Annor, F.; Esuneh, F.; Okoegwale, E.E. Metabolic Syndrome and Impaired Health-Related Quality of Life and in Non-Hispanic White, Non-Hispanic Blacks and Mexican-American Adults. Diabetes Metab. Syndr. Clin. Res. Rev. 2013, 7, 154-160. [CrossRef] [PubMed]

30. Raikkonen, K.; Matthews, K.A.; Kuller, L.H. Depressive Symptoms and Stressful Life Events Predict Metabolic Syndrome Among Middle-Aged Women: A Comparison of World Health Organization, Adult Treatment Panel III, and International Diabetes Foundation Definitions. Diabetes Care 2007, 30, 872-877. [CrossRef] [PubMed]

31. Eschweiler, G.W. Diagnostik und multimodale Therapie der Altersdepression: Neue Entwicklungen. Z Gerontol Geriat. 2017, 50, 99-105. [CrossRef] [PubMed] 